\title{
Early versus late recurrence of intrahepatic cholangiocarcinoma after resection with curative intent
}

\author{
X.-F. Zhang ${ }^{1,3}$, E. W. Beal ${ }^{3}$, F. Bagante ${ }^{8}$, J. Chakedis ${ }^{3}$, M. Weiss ${ }^{4}$, I. Popescu ${ }^{10}$, H. P. Marques ${ }^{11}$, \\ L. Aldrighetti ${ }^{9}$, S. K. Maithel ${ }^{5}$, C. Pulitano ${ }^{12}$, T. W. Bauer ${ }^{6}$, F. Shen ${ }^{2}$, G. A. Poultsides ${ }^{7}$, \\ O. Soubrane ${ }^{13}$, G. Martel $^{14}$, B. G. Koerkamp ${ }^{15}$, E. Itaru ${ }^{16}$ and T. M. Pawlik ${ }^{3}$ (I)
}

${ }^{1}$ Department of Hepatobiliary Surgery and Institute of Advanced Surgical Technology and Engineering, The First Affiliated Hospital of Xi'an Jiaotong University, Xi'an, and ${ }^{2}$ Department of Surgery, Eastern Hepatobiliary Surgery Hospital, Shanghai, China, Departments of Surgery, ${ }^{3}$ The Ohio State University, Wexner Medical Center, Columbus, Ohio, ${ }^{4}$ Johns Hopkins Hospital, Baltimore, Maryland, ${ }^{5}$ Emory University, Atlanta, Georgia, ${ }^{6}$ University of Virginia, Charlottesville, Virginia and ${ }^{7}$ Stanford University, Stanford, California, USA, ${ }^{8}$ Deparment of Surgery, University of Verona, Verona, and ${ }^{9}$ Department of Surgery, Ospedale San Raffaele, Milan, Italy, ${ }^{10}$ Department of Surgery, Fundeni Clinical Institute, Bucharest, Romania, ${ }^{11}$ Department of Surgery, Curry Cabral Hospital, Lisbon, Portugal, ${ }^{12}$ Department of Surgery, Royal Prince Alfred Hospital, University of Sydney, Sydney, New South Wales, Australia, ${ }^{13}$ Department of Hepatobiliopancreatic Surgery and Liver Transplantation, Assistance Publique - Hôpitaux de Paris, Beaujon Hospital, Clichy, France, ${ }^{14}$ Division of General Surgery, Department of Surgery, University of Ottawa, Ottawa, Ontario, Canada, ${ }^{15}$ Department of Surgery, Erasmus University Medical Centre, Rotterdam, The Netherlands, and ${ }^{16}$ Gastroenterological Surgery Division, Yokohama City University School of Medicine, Yokohama, Japan

Correspondence to: Professor T. M. Pawlik, Department of Surgery, The Ohio State University, Wexner Medical Center, 395 West 12th Avenue, Suite 670, Columbus, Ohio 43210, USA (e-mail: tim.pawlik@osumc.edu; @ @

\begin{abstract}
Background: The objective of this study was to investigate the characteristics, treatment and prognosis of early versus late recurrence of intrahepatic cholangiocarcinoma (ICC) after hepatic resection.

Methods: Patients who underwent resection with curative intent for ICC were identified from a multi-institutional database. Data on clinicopathological characteristics, initial operative details, timing and sites of recurrence, recurrence management and long-term outcomes were analysed.

Results: A total of 933 patients were included. With a median follow-up of 22 months, 685 patients (73.4 per cent) experienced recurrence of ICC; 406 of these (59.3 per cent) developed only intrahepatic disease recurrence. The optimal cutoff value to differentiate early (540 patients, 78.8 per cent) versus late $(145,21 \cdot 2$ per cent) recurrence was defined as 24 months. Patients with early recurrence had extrahepatic disease more often (44.1 per cent versus 28.3 per cent in those with late recurrence; $P<0.001$ ), whereas late recurrence was more often only intrahepatic (71.7 per cent versus 55.9 per cent for early recurrence; $P<0.001)$. From time of recurrence, overall survival was worse among patients who had early versus late recurrence (median 10 versus 18 months respectively; $P=0.029$ ). In multivariable analysis, tumour characteristics including tumour size, number of lesions and satellite lesions were associated with an increased risk of early intrahepatic recurrence. In contrast, only the presence of liver cirrhosis was independently associated with an increased likelihood of late intrahepatic recurrence (hazard ratio 1.99, 95 per cent c.i. $1 \cdot 11$ to $3 \cdot 56 ; P=0.019$ ).

Conclusion: Early and late recurrence after curative resection for ICC are associated with different risk factors and prognosis. Data on the timing of recurrence may inform decisions about the degree of postoperative surveillance, as well as help counsel patients with regard to their risk of recurrence.
\end{abstract}

Paper accepted 11 July 2017

Published online 28 November 2017 in Wiley Online Library (www.bjs.co.uk). DOI: 10.1002/bjs.10676

\section{Introduction}

Intrahepatic cholangiocarcinoma (ICC) is the second most common primary liver tumour after hepatocellular carcinoma (HCC), accounting for 10-15 per cent of all primary liver cancers ${ }^{1,2}$. Although relatively rare, ICC is a fatal malignancy, which often has a more aggressive tumour biology than $\mathrm{HCC}^{3}$. In fact, among patients who present with advanced and/or metastatic disease, the overall 5-year survival rate is dismal at just 5-10 per cent ${ }^{4}$. For the $20-40$ per cent of patients with ICC who present with operable disease, surgical resection remains the only potentially curative treatment option for $\mathrm{ICC}^{5,6}$. Even after resection with curative intent, the 5 -year survival rate is still only 
$20-35$ per cent ${ }^{4,7}$. The main reason for the poor long-term oncological outcomes relates to the incidence of recurrence, which can be as high as 54-71 per cent ${ }^{7-9}$.

Several studies have investigated the risk factors, as well as the management, associated with recurrent ICC after resection with curative intent ${ }^{7-9}$. The risk of recurrence has generally been associated with biological factors indicative of tumour aggressiveness, as well as technical factors such as a positive surgical margin ${ }^{7-9}$. In addition, similar to HCC, the majority of ICC recurrences after hepatic resection occur in the liver remnant ${ }^{7,8,10}$. In patients with HCC, the aetiology of recurrences has been attributed to either intrahepatic metastasis from the initial tumour or a de novo tumour ${ }^{10,11}$. In clinical practice, the differentiation between a recurrence and development of a de novo tumour can be challenging and relies largely on genetic or molecular studies of the clonal origin of the tumours ${ }^{12,13}$. Early recurrence after resection of HCC has been associated with certain tumour pathological characteristics, whereas late recurrence has been related to underlying liver disease ${ }^{14-17}$. In turn, early recurrence is more likely to be 'recurrent' disease, whereas late recurrence is more often a representation of a metachronous second primary lesion $^{14-17}$.

Although early versus late recurrence has been examined extensively among patients with HCC, the topic has been poorly studied in those with ICC. Data on risk factors, patterns of recurrence, and outcomes in patients with early versus late recurrence may have important implications for postoperative surveillance and adjuvant therapy, as well as management of the recurrence ${ }^{10,17}$. The objective of the present study was to define the risk factors, treatment and prognosis of patients with early versus late recurrence of ICC after surgery with curative intent. In addition, the implications of early versus late recurrence on long-term outcomes among patients with ICC were characterized.

\section{Methods}

Patients undergoing hepatic resection with curative intent for ICC from 1990 to 2016 at one of 14 major hepatobiliary centres in North America, Europe, Australia and Asia were included in the study. Patients with extrahepatic metastasis at the time of surgery and those undergoing palliative resection, ablation only or intra-arterial therapy only were excluded. Additionally, patients who were lost to follow-up, those who did not have detailed information regarding site of recurrence, and patients who died within 30 days of surgery were excluded. All patients were diagnosed with histologically confirmed ICC. The Institutional Review Boards of each participating institution approved the study.

\section{Data collection and follow-up}

Demographic and clinicopathological variables were collected for each patient. Liver cirrhosis was diagnosed based on histological examination of pathological specimens. Tumour size, number and morphology, vascular, perineural, biliary and adjacent organ invasion, lymph node metastasis and histological grade were also documented based on final pathology reports. Data on tumour stage were collected according to the AJCC seventh edition staging system ${ }^{18}$. Patients were followed regularly after surgery with assessment of serum carbohydrate antigen 19-9, carcinoembryonic antigen levels, and abdominal CT or MRI.

Recurrence was defined as suspicious imaging findings or biopsy-proven tumour. Sites of recurrence were categorized as intrahepatic, extrahepatic, or both intrahepatic and extrahepatic. Overall survival (OS) and recurrence-free survival were calculated from the date of surgery. OS after the first recurrence was calculated from the date of recurrence and was used to compare the outcome of patients with early and late recurrence.

\section{Treatment of recurrence}

When tumour recurrence was diagnosed, the therapeutic strategy was evaluated based on tumour location, number of tumours, general patient condition and liver function. Treatment with curative intent, including surgical re-resection, ablation or both, was considered for patients with only intrahepatic recurrence. Other treatments were individualized for patients with advanced recurrent disease, and included intra-arterial therapy, chemotherapy and radiotherapy, depending on disease extent and the patient's performance status.

\section{Statistical analysis}

Continuous variables are expressed as median (i.q.r.) and compared with Student's $t$ test or the Mann-Whitney $U$ test. Categorical variables are expressed as numbers and percentages, and compared with the $\chi^{2}$ test or Fisher's exact test. Kaplan-Meier curves with log rank tests were used to compare survival. Univariable and multivariable logistic regression models were used to determine factors associated with 'any site' and intrahepatic-only recurrence. Hazard ratios (HRs) and 95 per cent confidence intervals were estimated by means of multivariable analysis. Variables with a $P$ value of less than $0 \cdot 100$ in univariable analysis were entered into the multivariable model. A two-tailed $P$ value greater than $0 \cdot 050$ was considered statistically significant. Statistical analysis was performed using SPSS ${ }^{\circledR} 22.0$ (IBM, Armonk, New York, USA). 


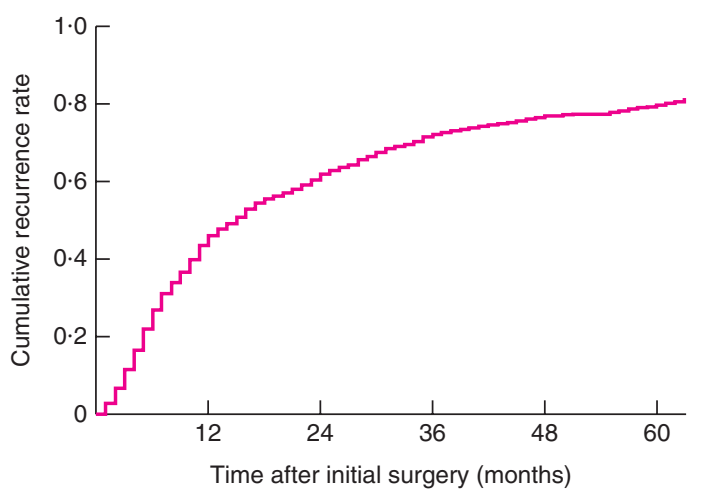

$\begin{array}{lllllll}\text { No. at risk } & 933 & 485 & 288 & 187 & 124 & 89\end{array}$

a Recurrence, all patients

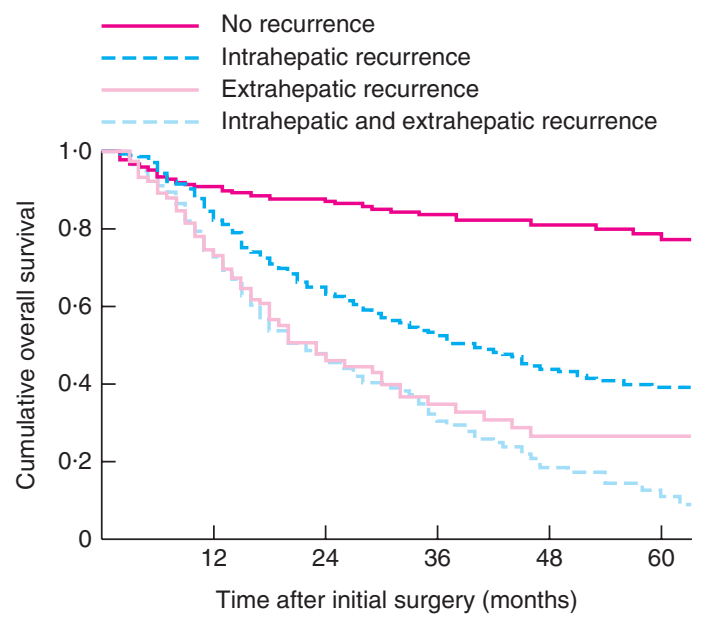

No. at risk

$\begin{array}{lcccccc}\text { No recurrence } & 248 & 193 & 132 & 109 & 76 & 54 \\ \text { Intrahepatic } & 406 & 317 & 214 & 137 & 84 & 58 \\ \text { Extrahepatic } & 94 & 63 & 32 & 18 & 10 & 7 \\ \begin{array}{l}\text { Intrahepatic and } \\ \quad \text { extrahepatic }\end{array} & 185 & 128 & 73 & 37 & 16 & 7\end{array}$

b Survival according to type of recurrence

Fig. 1 a Cumulative recurrence among patients with intrahepatic cholangiocarcinoma (ICC) who underwent surgery with curative intent. b Overall survival of patients according to type of recurrence after initial surgery for ICC. $P<0 \cdot 001$ (log rank test)

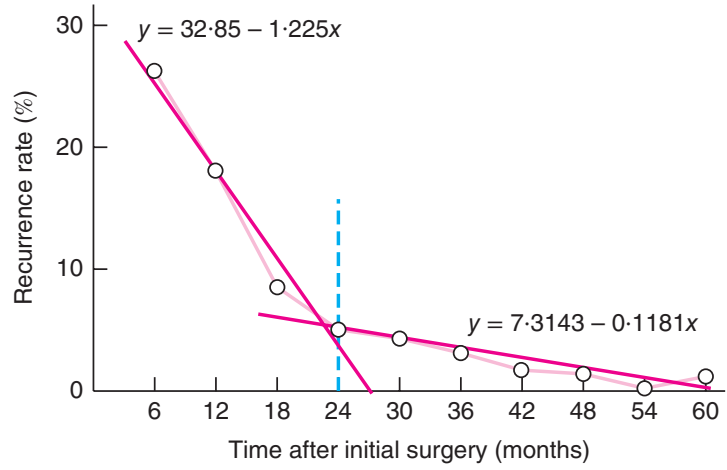

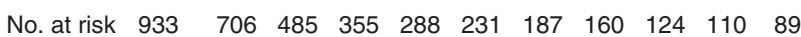

Fig. 2 Determination of the optimal cutoff value for early and late recurrence of intrahepatic cholangiocarcinoma (ICC).

Recurrence was divided into two periods according to the slope of the curves identified with linear regression. The function of the two lines was $y=32.85-1.225 x$ and $y=7.3143-0.1181 x$ respectively. The intercept value of the two lines was 23 months; 24 months was thus defined as the optimal cutoff value to differentiate early and late recurrence of ICC

\section{Results}

A total of 1142 patients were identified from the 14 institutions. Thirty-two patients were excluded because of extrahepatic metastasis at the time of surgery, palliative resection, ablation alone or intra-arterial therapy alone. A further 89 patients were lost to follow-up, did not have detailed information regarding site of recurrence (30 patients) or died within 30 days of surgery (58; in-hospital death rate $5 \cdot 1$ per cent) and were therefore excluded. A total 933 patients undergoing curative resection for ICC were included in the analysed cohort.

With a median follow-up of 22 months, 440 patients (47.2 per cent) had died. Cumulative 1-, 3 - and 5-year OS rates were 82,53 and 41 per cent respectively. Of these 440 patients, 397 (90.2 per cent) died from tumour recurrence and 43 (9.8 per cent) from other causes. Some 292 patients (31.3 per cent) were alive at last follow-up with tumour recurrence. The cumulative recurrence rate at 1,3 and 5 years was 44, 65 and 70 per cent respectively (Fig. 1a). In total, 685 patients (73.4 per cent) developed recurrence, of whom 406 (59.3 per cent) had intrahepatic disease only, 94 (13.7 per cent) had extrahepatic disease only, and 185 (27.0 per cent) had both intrahepatic and extrahepatic disease. The lungs, distal lymph nodes and peritoneum were the most common sites of extrahepatic recurrence $(23 \cdot 7,24 \cdot 7$ and $16 \cdot 1$ per cent respectively).

Patients with no postoperative recurrence had a better survival than those who developed ICC recurrence $(P<0.001)$ (Fig. 1b). Notably, patients who had recurrent intrahepatic disease alone had a longer median OS than 
Table 1 Clinical and pathological characteristics of patients with early versus late recurrence following initial surgery for intrahepatic cholangiocarcinoma

\begin{tabular}{|c|c|c|c|}
\hline & Early recurrence $(n=540)$ & Late recurrence $(n=145)$ & $P \dagger$ \\
\hline Age (years)* & $58(49-68)$ & $61(54-67)$ & $0.139 \ddagger$ \\
\hline Men & $313(58.0)$ & $74(51 \cdot 0)$ & 0.129 \\
\hline $\operatorname{BMI}\left(\mathrm{kg} / \mathrm{m}^{2}\right)^{*}$ & $25 \cdot 3(22 \cdot 3-28 \cdot 0)$ & $25 \cdot 2(22 \cdot 2-28 \cdot 0)$ & $0.889 \ddagger$ \\
\hline Liver cirrhosis & $62(11.5)$ & $31(21.4)$ & 0.002 \\
\hline Carbohydrate antigen 19-9 (units $/ \mathrm{ml})^{\star}$ & $53 \cdot 8(16 \cdot 0-272 \cdot 3)$ & $33.0(11.2-90.0)$ & $0.878 \neq$ \\
\hline Carcinoembryonic antigen $(\mathrm{ng} / \mathrm{ml})^{\star}$ & $2 \cdot 4(1 \cdot 3-4 \cdot 3)$ & $2 \cdot 2(1 \cdot 5-3 \cdot 6)$ & $0.911 \neq$ \\
\hline Tumour size $(\mathrm{cm})^{\star}$ & $6.5(4.8-9 \cdot 0)$ & $6.0(3.8-8.0)$ & $0.019 \ddagger$ \\
\hline Multiple lesions $(\geq 2)$ & $120(22 \cdot 2)$ & $16(11.0)$ & 0.002 \\
\hline Bilobar tumour & $102(18.9)$ & $21(14.5)$ & 0.272 \\
\hline \multicolumn{4}{|l|}{ Vascular invasion } \\
\hline Macro & $65(12 \cdot 0)$ & $13(9 \cdot 0)$ & 0.377 \\
\hline Micro & $155(28 \cdot 7)$ & $29(20 \cdot 0)$ & 0.044 \\
\hline Perineural invasion & $87(16 \cdot 1)$ & $20(13.8)$ & 0.604 \\
\hline Direct invasion of adjacent organs & $47(8.7)$ & $8(5 \cdot 5)$ & 0.300 \\
\hline Biliary invasion & $76(14 \cdot 1)$ & $17(11 \cdot 7)$ & 0.571 \\
\hline Satellite lesions & $152(28 \cdot 1)$ & $20(13.8)$ & $<0.001$ \\
\hline AJCC tumour category & & & 0.056 \\
\hline $\mathrm{T} 1-2$ & $413(76 \cdot 5)$ & $114(78 \cdot 6)$ & \\
\hline T3-4 & $101(18 \cdot 7)$ & $16(11.0)$ & \\
\hline Missing & $26(4 \cdot 8)$ & $15(10 \cdot 3)$ & \\
\hline AJCC node category & & & 0.009 \\
\hline NO & $284(52 \cdot 6)$ & $77(53 \cdot 1)$ & \\
\hline $\mathrm{N} 1-2$ & $117(21 \cdot 7)$ & $17(11.7)$ & \\
\hline $\mathrm{Nx}$ & $139(25 \cdot 7)$ & $51(35 \cdot 2)$ & \\
\hline Histological grade & & & 0.263 \\
\hline Well to moderately differentiated & $422(78 \cdot 1)$ & $117(80 \cdot 7)$ & \\
\hline Poorly to undifferentiated & $100(18.5)$ & $20(13.8)$ & \\
\hline Missing & $18(3 \cdot 3)$ & $8(5 \cdot 5)$ & \\
\hline Morphological type & & & 0.147 \\
\hline Mass-forming & $428(78.2)$ & $106(73.1)$ & \\
\hline Papillary & $13(2 \cdot 4)$ & $8(5.5)$ & \\
\hline Periductal infiltrating & $24(4.4)$ & $6(4 \cdot 1)$ & \\
\hline Mass-forming + periductal infiltrating & $52(9.6)$ & $9(6 \cdot 2)$ & \\
\hline Missing & $23(4 \cdot 3)$ & $16(11.0)$ & \\
\hline Resection procedure & & & 0.557 \\
\hline Minor & $220(40 \cdot 7)$ & $63(43.4)$ & \\
\hline Major & $320(59 \cdot 3)$ & $82(56 \cdot 6)$ & \\
\hline Ro resection & $472(87.4)$ & $130(89 \cdot 7)$ & 0.566 \\
\hline Margin distance $(\mathrm{mm})$ & & & 0.013 \\
\hline$<1$ & $68(12.6)$ & $15(10 \cdot 3)$ & \\
\hline $1-4$ & $197(36 \cdot 5)$ & $41(28 \cdot 3)$ & \\
\hline $5-9$ & $115(21 \cdot 3)$ & $27(18.6)$ & \\
\hline$\geq 10$ & $126(23 \cdot 3)$ & $53(36 \cdot 6)$ & \\
\hline Missing & $34(6 \cdot 3)$ & $9(6 \cdot 2)$ & \\
\hline Major vascular resection & $61(11 \cdot 3)$ & $15(10 \cdot 3)$ & 0.882 \\
\hline Bile duct resection & $99(18.3)$ & $22(15 \cdot 2)$ & 0.462 \\
\hline Lymphadenectomy & $269(49 \cdot 8)$ & $69(47.6)$ & 0.634 \\
\hline Intraoperative blood loss $(\mathrm{ml})^{*}$ & $450(200-800)$ & $400(200-600)$ & $0.405 \ddagger$ \\
\hline Duration of surgery $(\mathrm{min})^{\star}$ & $200(120-310)$ & $205(120-355)$ & $0.773 \ddagger$ \\
\hline Adjuvant chemo/radiotherapy & $197(36 \cdot 5)$ & $48(33.1)$ & 0.294 \\
\hline Postoperative complications & $189(35 \cdot 0)$ & $53(36 \cdot 6)$ & 0.729 \\
\hline
\end{tabular}

Values in parentheses are percentages unless indicated otherwise; *values are median (i.q.r.). $\dagger \chi^{2}$ or Fisher's exact test, except $\ddagger$ Student’s $t$ test or Mann-Whitney $U$ test. 


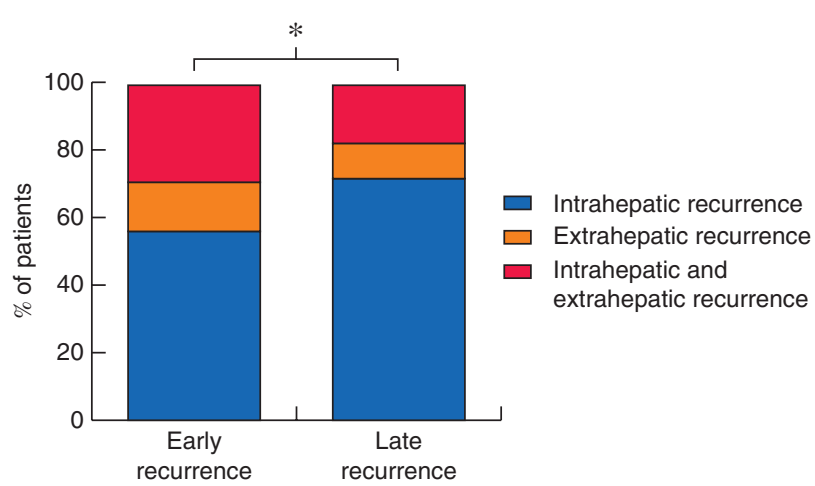

Fig. 3 Sites of recurrence in patients who had early or late recurrence following surgery with curative intent for intrahepatic cholangiocarcinoma. ${ }^{*} P=0.003\left(\chi^{2}\right.$ test $)$

those with only extrahepatic recurrent disease (40 versus 23 months respectively; $P=0.003$ ), as well as patients who developed both intrahepatic and extrahepatic disease (40 versus 22 months; $P<0 \cdot 001$ ) (Fig. 1b).

\section{Optimal cutoff value for early and late recurrence}

To determine the optimal cutoff value to distinguish between early and late recurrence, recurrence was evaluated at 6 -month time points. Twenty-four months was defined as the optimal cutoff value, as explained in Fig. 2.

Clinicopathological data and outcomes after recurrence were analysed and compared between the early and late recurrence groups.

\section{Outcomes following early and late recurrence at any site}

The time duration from the date of initial hepatic surgery to tumour recurrence was documented among the 685 patients with recurrence. A total of 540 patients $(78.8$ per cent) who developed recurrence within 24 months were defined as having early recurrence, and 145 (21.2 per cent) who had recurrence 24 months or more after first hepatic surgery were defined as having late recurrence. Although many of the clinicopathological and operative data from the time of initial surgery were comparable between the two groups, liver cirrhosis was more common among patients who experienced a late versus an early recurrence $(P=0.002)$ (Table 1$)$. Hepatitis B virus $(\mathrm{HBV})$ and hepatitis $\mathrm{C}$ virus (HCV) infection were the two most common causes of liver cirrhosis: 73 (78 per cent) of the 93 patients with liver cirrhosis who developed recurrence had hepatitis. Early recurrence occurred more commonly in patients with tumours that had more aggressive biological

Table 2 Risk factors for early and late recurrence of intrahepatic cholangiocarcinoma at any site

\begin{tabular}{|c|c|c|c|c|c|c|}
\hline & \multicolumn{3}{|c|}{ Early recurrence $(n=540)$} & \multicolumn{3}{|c|}{ Late recurrence $(n=145)$} \\
\hline & \multirow[b]{2}{*}{ Univariable $P$} & \multicolumn{2}{|c|}{ Multivariable analysis } & \multirow[b]{2}{*}{ Univariable $P$} & \multicolumn{2}{|c|}{ Multivariable analysis } \\
\hline & & Hazard ratio & $P$ & & Hazard ratio & $P$ \\
\hline $\operatorname{Sex}(M: F)$ & 0.256 & & & 0.336 & & \\
\hline Liver cirrhosis & 0.008 & $0.81(0.52,1.19)$ & 0.252 & 0.029 & $1.89(1.09,3.26)$ & 0.023 \\
\hline Tumour size $(\mathrm{cm})$ & $<0.001$ & & & 0.244 & & \\
\hline$\leq 5$ & & 1.00 (reference) & & & & \\
\hline $5-10$ & & $1.67(1.02,2.90)$ & 0.038 & & & \\
\hline$\geq 10$ & & $2.12(1.49,3.04)$ & $<0.001$ & & & \\
\hline Multiple tumours & $<0.001$ & $1.18(0.72,1.93)$ & 0.507 & 1.000 & & \\
\hline Bilobar disease & 0.304 & & & 0.459 & & \\
\hline Macrovascular invasion & 0.084 & $1 \cdot 19(0 \cdot 74,2 \cdot 21)$ & 0.447 & 0.756 & & \\
\hline Microvascular invasion & 0.018 & $1.34(0.86,2 \cdot 14)$ & 0.189 & 0.702 & & \\
\hline Perineural invasion & 0.084 & $1.08(0.67,1.74)$ & 0.816 & 0.419 & & \\
\hline Biliary invasion & 0.468 & & & 0.866 & & \\
\hline Direct invasion of adjacent organs & 0.002 & $1.71(0.73,4.16)$ & $0 \cdot 252$ & $0 \cdot 156$ & & \\
\hline Satellite lesions & $<0.001$ & $2 \cdot 0(1 \cdot 32,3 \cdot 15)$ & 0.002 & 0.640 & & \\
\hline Poorly differentiation to undifferentiated & 0.023 & $1.13(0.70,1.68)$ & 0.678 & 0.637 & & \\
\hline AJCC tumour category & 0.008 & & & 0.871 & & \\
\hline $\mathrm{T} 1-2$ & & 1.00 (reference) & & & & \\
\hline T3-4 & & $1 \cdot 0(0 \cdot 64,1 \cdot 66)$ & 0.944 & & & \\
\hline AJCC node category & $<0.001$ & & & 0.379 & & \\
\hline NO & & 1.00 (reference) & & & & \\
\hline N1 & & $1.3(1.01,1.63)$ & 0.028 & & & \\
\hline Adjuvant chemo/radiotherapy & $<0.001$ & $0.67(0.46,0.97)$ & 0.029 & 0.022 & $0.7(0.4,1.2)$ & 0.218 \\
\hline
\end{tabular}

Values in parentheses are 95 per cent confidence intervals. 

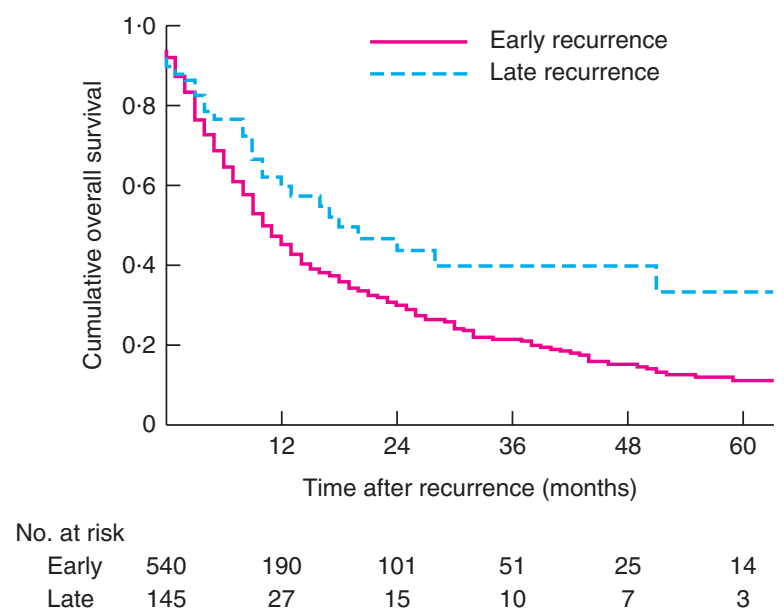

a Overall survival after diagnosis of recurrence

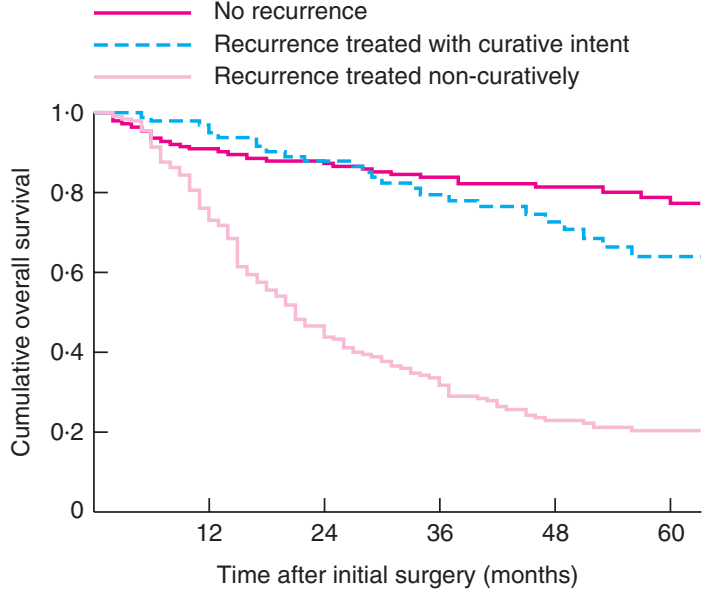

No. at risk

$\begin{array}{lllllll}\text { No recurrence } & 248 & 193 & 132 & 109 & 76 & 54\end{array}$

$\begin{array}{lllllll}\text { Curative } & 103 & 91 & 68 & 54 & 36 & 24\end{array}$

$\begin{array}{lllllll}\text { Non-curative } & 224 & 160 & 87 & 54 & 30 & 23\end{array}$

b Overall survival according to treatment of recurrence

Fig. 4 Overall survival a from date of diagnosis of recurrence stratified by early versus late recurrence and $\mathbf{b}$ following initial surgery for intrahepatic cholangiocarcinoma (ICC) in patients with no recurrence, patients with recurrence of ICC treated with curative intent and those with recurrence treated non-curatively. a $P=0 \cdot 029$, b $P<0 \cdot 001$ (log rank test)

features, including larger size $(P=0 \cdot 019)$, multiple lesions $(P=0.002)$, and the presence of microvascular invasion $(P=0.044)$ or satellite lesions $(P<0 \cdot 001)$. Although the type and extent of surgery were no different between the two groups, more patients with early recurrence had a narrow surgical margin than those with late recurrence (margin less than $1 \mathrm{~cm}$ : 70.4 versus 57.2 per cent respectively; $P=0.003$ ).

Intrahepatic-only recurrence was more common in patients who had a late recurrence (104 (71.7 per cent) versus 302 (55.9 per cent) in those with early recurrence; $P<0.001)$, whereas extrahepatic recurrence was more common in patients with an early recurrence (238 (44.1 per cent) versus 41 (28.3 per cent) with a late recurrence; $P<0.001)$ (Fig. 3).

Factors associated with early recurrence after initial hepatectomy were investigated among all 933 patients in the analysed cohort. Factors related to late recurrence were investigated among the 393 patients who were free of recurrence in the first 24 months after the index operation. Tumour characteristics, including increasing tumour size, satellite lesions and lymph node metastasis, were associated with an increased likelihood of early recurrence, whereas adjuvant chemo/radiotherapy was associated with a decreased risk of early recurrence (Table 2). In contrast, only the presence of liver cirrhosis was independently associated with an increased risk of late recurrence.
Following recurrence, median OS was lower among patients who developed early recurrence than in those with late recurrence (10 versus 18 months respectively; $P=0.029)$ (Fig. 4a).

\section{Risk factors and outcome after early and late intrahepatic-only recurrence}

For intrahepatic-only recurrence, tumour size, number of tumours and satellite lesions were independent risk factors for early intrahepatic recurrence (Table 3). Liver cirrhosis was the only independent risk factor for late recurrence. Of the 406 patients who had an intrahepatic recurrence, 327 (80.5 per cent) had treatment for the recurrent disease (274 with early and 53 with late intrahepatic recurrence). One-quarter of patients (70 of $274,25.5$ per cent) with early intrahepatic recurrence had treatment with curative intent (surgical resection, 61; ablation, 9), whereas 62 per cent (33 of 53) of those with late intrahepatic recurrence underwent potentially curative therapy (surgical resection, 20; ablation, 13) $(P<0 \cdot 001)$.

Median OS after resection and ablation were comparable (124 months versus median not reached for ablation; $P=0.543)$. Palliative treatments including repeat intra-arterial therapy and systemic chemotherapy were undertaken in 74.5 per cent (204 of 274) of patients with early intrahepatic recurrence and 38 per cent (20 of 53) of those with late intrahepatic recurrence. 
Table 3 Risk factors for early and late intrahepatic-only recurrence of intrahepatic cholangiocarcinoma

\begin{tabular}{|c|c|c|c|c|c|}
\hline & \multicolumn{3}{|c|}{ Early recurrence $(n=302)$} & \multirow{2}{*}{\multicolumn{2}{|c|}{$\begin{array}{c}\text { Late recurrence }(n=104) \\
\text { Univariable analysis }\end{array}$}} \\
\hline & \multirow[b]{2}{*}{ Univariable $P$} & \multicolumn{2}{|c|}{ Multivariable analysis } & & \\
\hline & & Hazard ratio & $P$ & Hazard ratio & $P$ \\
\hline $\operatorname{Sex}(M: F)$ & 0.529 & & & & 0.171 \\
\hline Liver cirrhosis & 0.063 & $0.84(0.53,1.27)$ & 0.337 & $1.99(1.11,3.56)$ & 0.019 \\
\hline Tumour size $(\mathrm{cm})$ & $<0.001$ & & & & 0.436 \\
\hline$\leq 5$ & & 1.00 (reference) & & & \\
\hline $5-10$ & & $1.58(0.92,2.72)$ & 0.105 & & \\
\hline$\geq 10$ & & $1.87(1.34,2.81)$ & 0.001 & & \\
\hline Multiple tumours & $<0.001$ & $1.62(1.03,2.72)$ & 0.052 & & 0.644 \\
\hline Bilobar disease & 0.726 & & & & 0.429 \\
\hline Macrovascular invasion & 0.985 & & & & 0.834 \\
\hline Microvascular invasion & 0.064 & $1.09(0.74,1.73)$ & 0.632 & & 0.223 \\
\hline Perineural invasion & 0.095 & $1.16(0.69,1.87)$ & 0.577 & & 0.767 \\
\hline Biliary invasion & 0.895 & & & & 0.320 \\
\hline Direct invasion of adjacent organs & 0.037 & $1.58(0.56,4.24)$ & 0.367 & & 0.457 \\
\hline Satellite lesions & $<0.001$ & $1.85(1.22,3.13)$ & 0.008 & & 1.000 \\
\hline Poorly differentiated to undifferentiated & 0.166 & & & & 0.725 \\
\hline R1 margin & 0.069 & $1.33(0.74,2.30)$ & 0.476 & & 0.633 \\
\hline AJCC tumour category & 0.116 & & & & 0.352 \\
\hline $\mathrm{T} 1-2$ & & & & & \\
\hline T3-4 & & & & & \\
\hline AJCC node category & 0.001 & & 0.469 & & 1.000 \\
\hline No & & 1.00 (reference) & & & \\
\hline N1 & & $1.14(0.93,1.32)$ & & & \\
\hline Adjuvant chemo/radiotherapy & 0.008 & $0.66(0.52,1.11)$ & 0.142 & & 0.311 \\
\hline
\end{tabular}

Values in parentheses are 95 per cent confidence intervals.

From the time of ICC recurrence, patients with early intrahepatic disease tended to have a worse OS than those with late intrahepatic disease (median 13 versus 24 months respectively; $P=0 \cdot 190$ ). However, subsequent OS following curative treatment of the recurrence was no different in early and late recurrence groups (median OS 51 versus 55 months respectively; $P=0 \cdot 654$ ). Following treatment with curative intent of the recurrence (103 of 327 patients: 70 of 274 with early and 33 of 53 with late intrahepatic recurrence), 1-, 3- and 5-year OS rates were 94.8, 79.5 and 63.7 per cent respectively, comparable to rates in the 248 patients who had no recurrence $(91.1,83.7$ and 77.1 per cent respectively) $(P=0 \cdot 270)$ (Fig. $4 b)$. Of note, patients with intrahepatic recurrence who did not undergo treatment with curative intent (224 of 327: 204 with early and 20 with late intrahepatic recurrence) had worse long-term outcomes (1-, 3- and 5-year OS rates of 73.1, 31.5 and 20.1 per cent respectively; $P<0 \cdot 001)$.

\section{Discussion}

Even when surgical resection with curative intent is performed, the prognosis of patients with ICC is poor owing to a high incidence of recurrence, which may occur early or late. The optimal time point to differentiate early versus late recurrence of ICC had not been defined previously. Based on a large international cohort of patients with ICC, 2 years was defined empirically as an optimal cutoff to distinguish early versus late recurrence. In particular, early recurrence was associated with tumour-specific factors such as large multiple tumours with microvascular invasion and lymph nodes metastasis. In contrast, late recurrence was related more to the underlying non-tumorous liver parenchyma, in particular the presence of cirrhosis. Although only genetic and molecular studies of clonal origin can definitively differentiate a recurrence from a second primary, the present study strongly suggests that early recurrence of ICC is most likely a recurrence of the initial tumour, whereas late recurrence is probably a second primary cancer and potentially related to the background liver. These findings are important, as the data strongly suggest that surveillance needs to be focused more intensely on the first 2 years after resection of ICC, especially among patients with certain clinical features. The data also provide prognostic information to help counsel patients and potentially guide adjuvant treatment planning.

In the present study, the time course of recurrence after surgical resection of initial tumours was analysed empirically and the majority of recurrences were noted to occur within 24 months, with the rate of recurrence 
declining after this time point. Of note, early recurrence was strongly associated with tumour characteristics including lesion size and the presence of satellite lesions. Given the short time to recurrence, disease that recurs within 24 months may be a consequence of intrahepatic metastasis, microsatellite lesions or even occult residual disease that was present at the time of the first operation. As such, special attention should be paid to patients with multiple large tumours and satellite lesions during the preoperative evaluation interval. Although improvement in accuracy of imaging modalities can help identify tumours and metastatic lesions, as many as one-third of patients have occult metastatic or locally advanced disease $\mathrm{e}^{5,19}$. Of note, although not associated with early intrahepatic-only recurrence, lymph node metastasis was associated with early any-site recurrence. Moreover, patients who recurred early were more likely to present with extrahepatic recurrence. In turn, patients who experienced an early recurrence had a worse long-term outcome than those with a late recurrence ${ }^{20}$. Similarly, early recurrence of HCC and colorectal liver metastasis after initial hepatectomy have been associated with worse long-term outcomes ${ }^{16,21,22}$. As such, adjuvant therapy following resection of ICC should be considered to decrease the probability of tumour recurrence after surgical resection ${ }^{23,24}$. Further, it has been reported ${ }^{25}$ that use of chemotherapy is associated with a survival benefit for patients with ICC and nodal metastasis and advanced tumour stage.

Although tumour factors were associated with early recurrence, underlying liver cirrhosis was the only factor associated with late recurrence. Previous studies ${ }^{7-9}$ noted that recurrence following resection of ICC with curative intent was associated with liver cirrhosis, as well as tumour characteristics. However, none of these studies specifically examined the timing of recurrence relative to the pattern of recurrent disease or time of recurrence. The present study not only identified liver cirrhosis as a cause of intrahepatic-only recurrence, but also noted that it was associated specifically with a late timing of recurrence. In addition, many of the patients who experienced a late recurrence in the setting of cirrhosis also had hepatitis. These data strongly imply that the late 'recurrence' of ICC may instead be the development of a second primary tumour. Cirrhosis, secondary to $\mathrm{HBV}$ and $\mathrm{HCV}$ infection, primary biliary disease, alcoholic and non-alcoholic steatohepatitis, can be associated with an increased risk of ICC development ${ }^{26-30}$. Hepatocytes and cholangiocytes have the same progenitor cell, and therefore both $\mathrm{HBV}$ and HCV may induce carcinogenesis in the two cell types by a similar mechanism ${ }^{27,28}$. It has previously been proposed ${ }^{31}$ to classify ICC as 'conventional' (without underlying liver disease) or 'unconventional' (developing in a background of non-biliary chronic liver disease and cirrhosis). As liver cirrhosis is not so common in patients with ICC as in those with HCC, other factors may account for the development of metachronous recurrent disease in patients with 'conventional' ICC. Further studies on the molecular signatures of late recurrent disease are needed to help classify recurrent $\mathrm{ICC}^{32}$.

A subset of patients with intrahepatic recurrence underwent repeated attempts at curative therapy. Among this subset of patients, surgical resection and ablation were both employed. It has been noted previously ${ }^{20}$ that local management, such as surgery, transarterial chemoembolization and radiofrequency ablation, are effective in selected patients with localized intrahepatic and extrahepatic recurrence. Similarly, in the present study, the 5-year OS rate of patients treated with curative intent for their recurrence was 63.7 per cent, which was not statistically different from that of 77.1 per cent among patients who never experienced a recurrence. Similar good outcomes for treatment of recurrent HCC have been published previously ${ }^{16}$. Moreover, retreatment with curative intent of patients who experienced early recurrence achieved postrecurrence survival comparable with that of patients who developed late recurrence, and curative treatments should be considered for patients with tumour recurrence within even 2 years of initial first surgery.

\section{Acknowledgements}

X.-F. Z. was supported in part by the China Scholarship Council.

Disclosure: The authors declare no conflict of interest.

\section{References}

1 Aljiffry M, Abdulelah A, Walsh M, Peltekian K, Alwayn I, Molinari M. Evidence-based approach to cholangiocarcinoma: a systematic review of the current literature. 7 Am Coll Surg 2009; 208: 134-147.

2 Khan SA, Toledano MB, Taylor-Robinson SD. Epidemiology, risk factors, and pathogenesis of cholangiocarcinoma. HPB (Oxford) 2008; 10: 77-82.

3 Zhou XD, Tang ZY, Fan J, Zhou J, Wu ZQ, Qin LX et al. Intrahepatic cholangiocarcinoma: report of 272 patients compared with 5829 patients with hepatocellular carcinoma. 7 Cancer Res Clin Oncol 2009; 135: 1073-1080.

4 Mavros MN, Economopoulos KP, Alexiou VG, Pawlik TM. Treatment and prognosis for patients with intrahepatic cholangiocarcinoma: systematic review and meta-analysis. FAMA Surg 2014; 149: 565-574.

5 Weber SM, Jarnagin WR, Klimstra D, DeMatteo RP, Fong Y, Blumgart LH. Intrahepatic cholangiocarcinoma: 
resectability, recurrence pattern, and outcomes. $7 \mathrm{Am}$ Coll Surg 2001; 193: 384-391.

6 Amini N, Ejaz A, Spolverato G, Kim Y, Herman JM, Pawlik TM. Temporal trends in liver-directed therapy of patients with intrahepatic cholangiocarcinoma in the United States: a population-based analysis. 7 Surg Oncol 2014; 110: 163-170.

7 Spolverato G, Kim Y, Alexandrescu S, Marques HP, Lamelas J, Aldrighetti L et al. Management and outcomes of patients with recurrent intrahepatic cholangiocarcinoma following previous curative-intent surgical resection. Ann Surg Oncol 2016; 23: 235-243.

8 Hyder O, Hatzaras I, Sotiropoulos GC, Paul A, Alexandrescu S, Marques H et al. Recurrence after operative management of intrahepatic cholangiocarcinoma. Surgery 2013; 153: 811-818.

9 Sulpice L, Rayar M, Boucher E, Pracht M, Meunier B, Boudjema K. Treatment of recurrent intrahepatic cholangiocarcinoma. Br 7 Surg 2012; 99: 1711-1717.

10 Poon RT. Differentiating early and late recurrences after resection of HCC in cirrhotic patients: implications on surveillance, prevention, and treatment strategies. Ann Surg Oncol 2009; 16: $792-794$.

11 Poon RT, Fan ST, Lo CM, Liu CL, Ng IO, Wong J. Long-term prognosis after resection of hepatocellular carcinoma associated with hepatitis B-related cirrhosis. 7 Clin Oncol 2000; 18: 1094-1101.

12 Chen PJ, Chen DS, Lai MY, Chang MH, Huang GT, Yang $\mathrm{PM}$ et al. Clonal origin of recurrent hepatocellular carcinomas. Gastroenterology 1989; 96: 527-529.

$13 \mathrm{Ng}$ IO, Guan XY, Poon RT, Fan ST, Lee JM. Determination of the molecular relationship between multiple tumour nodules in hepatocellular carcinoma differentiates multicentric origin from intrahepatic metastasis. F Pathol 2003; 199: 345-353.

14 Poon RT, Fan ST, Ng IO, Lo CM, Liu CL, Wong J. Different risk factors and prognosis for early and late intrahepatic recurrence after resection of hepatocellular carcinoma. Cancer 2000; 89: 500-507.

15 Imamura H, Matsuyama Y, Tanaka E, Ohkubo T, Hasegawa $\mathrm{K}$, Miyagawa $\mathrm{S}$ et al. Risk factors contributing to early and late phase intrahepatic recurrence of hepatocellular carcinoma after hepatectomy. 7 Hepatol 2003; 38: 200-207.

16 Portolani N, Coniglio A, Ghidoni S, Giovanelli M, Benetti A, Tiberio GA et al. Early and late recurrence after liver resection for hepatocellular carcinoma: prognostic and therapeutic implications. Ann Surg 2006; 243: 229-235.

17 Cucchetti A, Piscaglia F, Caturelli E, Benvegnù L, Vivarelli $\mathrm{M}$, Ercolani G et al. Comparison of recurrence of hepatocellular carcinoma after resection in patients with cirrhosis to its occurrence in a surveilled cirrhotic population. Ann Surg Oncol 2009; 16: 413-422.

18 Edge SB, Compton CC, Fritz AG, Greene FL, Trotti A. AfCC Cancer Staging Manual (7th edn). Springer: New York, 2010.

19 Goere D, Wagholikar GD, Pessaux P, Carrere N, Sibert A, Vilgrain $\mathrm{V}$ et al. Utility of staging laparoscopy in subsets of biliary cancers: laparoscopy is a powerful diagnostic tool in patients with intrahepatic and gallbladder carcinoma. Surg Endosc 2006; 20: 721-725.

20 Park HM, Yun SP, Lee EC, Lee SD, Han SS, Kim SH et al. Outcomes for patients with recurrent intrahepatic cholangiocarcinoma after surgery. Ann Surg Oncol 2016; 23: $4392-4400$.

21 Vigano L, Capussotti L, Lapointe R, Barroso E, Hubert C, Giuliante $\mathrm{F}$ et al. Early recurrence after liver resection for colorectal metastases: risk factors, prognosis, and treatment. A LiverMetSurvey-based study of 6025 patients. Ann Surg Oncol 2014; 21 : 1276-1286.

22 Shah SA, Greig PD, Gallinger S, Cattral MS, Dixon E, Kim $\mathrm{RD}$ et al. Factors associated with early recurrence after resection for hepatocellular carcinoma and outcomes. $7 \mathrm{Am}$ Coll Surg 2006; 202: 275-283.

23 Gil E, Joh JW, Park HC, Yu JI, Jung SH, Kim JM. Predictors and patterns of recurrence after curative liver resection in intrahepatic cholangiocarcinoma, for application of postoperative radiotherapy: a retrospective study. World f Surg Oncol 2015; 13: 227.

24 Dhanasekaran R, Hemming AW, Zendejas I, George T, Nelson DR, Soldevila-Pico C et al. Treatment outcomes and prognostic factors of intrahepatic cholangiocarcinoma. Oncol Rep 2013; 29: 1259-1267.

25 Miura JT, Johnston FM, Tsai S, George B, Thomas J, Eastwood D et al. Chemotherapy for surgically resected intrahepatic cholangiocarcinoma. Ann Surg Oncol 2015; 22: 3716-3723.

26 Welzel TM, Graubard BI, El-Serag HB, Shaib YH, Hsing AW, Davila JA et al. Risk factors for intrahepatic and extrahepatic cholangiocarcinoma in the United States: a population-based case-control study. Clin Gastroenterol Hepatol 2007; 5: 1221-1228.

27 Shaib YH, El-Serag HB, Nooka AK, Thomas M, Brown TD, Patt YZ et al. Risk factors for intrahepatic and extrahepatic cholangiocarcinoma: a hospital-based case-control study. Am $\mathcal{f}$ Gastroenterol 2007; 102: 1016-1021.

28 Shaib YH, El-Serag HB, Davila JA, Morgan R, McGlynn KA. Risk factors of intrahepatic cholangiocarcinoma in the United States: a case-control study. Gastroenterology 2005; 128: 620-626.

29 Zhou Y, Zhao Y, Li B, Huang J, Wu L, Xu D et al. Hepatitis viruses infection and risk of intrahepatic cholangiocarcinoma: evidence from a meta-analysis. BMC Cancer 2012; 12: 289.

30 Sorensen HT, Friis S, Olsen JH, Thulstrup AM, Mellemkjaer L, Linet $M$ et al. Risk of liver and other types of cancer in patients with cirrhosis: a nationwide cohort study in Denmark. Hepatology 1998; 28: 921-925.

31 Sempoux C, Jibara G, Ward SC, Fan C, Qin L, Roayaie S et al. Intrahepatic cholangiocarcinoma: new insights in pathology. Semin Liver Dis 2011; 31: 49-60.

32 Zou S, Li J, Zhou H, Frech C, Jiang X, Chu JS et al. Mutational landscape of intrahepatic cholangiocarcinoma. Nat Commun 2014; 5: 5696. 